\title{
Divided disasters: Examining the implications of the conflict-disaster nexus for distanced crises in the Philippines.
}

Jessica Field

\begin{abstract}
"Divided disasters" are conflicts and natural hazard-induced disasters that occur simultaneously, but in different locations within the same national boundaries. They place pressure on the same national governance structures, draw on the same international and national humanitarian resources, and can therefore mutually reinforce challenges and risks for the affected populations. Yet, as this paper argues, the impact does not come from the direct interaction of the two crises. It comes from, in part, the management of humanitarian responses to them - namely, through the re-prioritisation of attention and re-deployment of resources as driven by imperatives for 'the good project'. Using the case study of the Philippines, and the parallel emergencies of Typhoon Haiyan and the spike in violence in Mindanao in 2013, this paper explores the organisational drivers of humanitarian responses to divided disasters, and examines their implications for the crisis-affected populations.
\end{abstract}

Keywords: Conflict, disaster, Philippines, humanitarianism, aid effectiveness, non-governmental organisations (NGOs).

\section{Introduction}

There has been a surge of academic and policy literature in recent years exploring the effects of the conflict-disaster nexus, which captures the linkages between conflicts, natural hazard-induced disasters, and the types of humanitarian responses that should be mobilised when they occur simultaneously (Peters and Budimir, 2016; UNDP, 2011; Hyndman, 2011; Le Billon and Waizenegger, 2007; Brancati, 2007). This focus has come partly as a result of increased attention on a number of recent rapid-onset disasters that have occurred in conflict zones, or fragile contexts, such as the 2014 floods in the Kashmir Valley in India, the 2010 earthquake in Haiti, and the 2009 floods in rural Somalia (Brancati, 2007; UNDP, 2011; Peters and Budimir, 2016).

When analysing the effects of the conflict-disaster nexus, the literature tends to take three main tracks of enquiry, exploring whether: a) disasters cause or exacerbate conflict (Peters and Budimir, 2016; Eastin, 2015; Brancati, 2007); b) disasters offer new opportunities for conflict resolution (Kelman, 2011; Kreutz, 2012; Zeccola, 2011; Gaillard et al, 2008); or c) what the effects of the conflict-disaster interface are on people's lives and vulnerabilities (Walch, 2014; Le Billon and Waizenegger, 2007). Within much of the discussion, there is a recognition of the way that disasters 
and conflict can be mutually reinforcing, in that fragility and conflict can turn an environmental 'hazard' into a disaster, or - in a context of conflict or chronic violence - disasters can 'exacerbate the challenges people already face and create new risks' (Mitra and Vivekananda, 2015).

Nevertheless, these tracks of enquiry tend to miss a key area of interrogation: what are the impacts of a simultaneous conflict and natural hazard-induced disaster, when they occur in different locations within the same state? This, I will term "divided disasters". "Divided disasters" must be considered as part of the conflict-disaster nexus as, more often than not, a simultaneous, but distanced, conflict and natural disaster will place pressure on the same national governance structures, will draw on the same international and national humanitarian resources, and can therefore mutually reinforce challenges and risks for the affected populations.

Considering "divided disasters" as mutually reinforcing phenomena raises some interesting questions about vulnerability and responsibility. While dual disasters in the same locale invite immediate analysis on the impacts of the crises (in other words, the disaster and the conflict) and how those crises events, and their associated responses, directly interact with each other to cause or exacerbate challenges and vulnerabilities (Zeccola, 2011; Waizenegger and Hyndman, 2010), divided disasters invite immediate analysis of the responses, and how the (re)deployment of resources to one event may cause or exacerbate challenges in the other. This is because, in a divided disasters context, the disaster and the conflict do not directly interact. Two significant ways that a conflictaffected population can be impacted by a natural hazard-induced disaster that happens elsewhere or vice versa - is if attention and resources from their emergency are (re)deployed and/or if governance structures that govern both of their territories are impacted, causing disruption (through, for example, the deaths of senior officials in the emergency, or the disruption of central government services) $)^{2}$. In this paper, I am particularly interested in exploring the former point: what are the implications of attention and resource (re)deployment in the case of divided disasters? What

\footnotetext{
${ }^{1}$ The literature exploring the impact of conflict and natural disasters that occur in the same locale uses the term "dual disasters", and includes contexts where the overlap between emergencies may only be slight (Hyndman 2011; Zeccola 2011; Waizenegger and Hyndman 2010). "Divided disasters" merit a separate term as an extension of the dual disasters debate, because it accounts for contexts where, through geographical distance, the affected populations are distinct and therefore national/international actors may overlook (consciously or otherwise) their linkages. For example, Mali was in conflict in its northern region when it was hit in the southern part of the country by the severe West and Central African floods in 2012. Jammu and Kashmir, too, witnessed divided disasters in 2010, with a devastating cloudburst hitting Leh, Ladakh in August of that year while there was ongoing conflict in the Kashmir valley. The Philippines frequently experiences divided disasters, as it has a long-running conflict in its southern region, and experiences regular natural hazard-induced disasters in the north and east of the country.

${ }^{2}$ An example of this second instance in a proximate disaster context is Haiti after the 2010 earthquake, where many civil servants died, the main branches of government were destroyed and 'the earthquake's effect on the logistical aspects of government operations was severe' (Crane et al, 2010: 33). The extent to which disruption to central government services has affected distant conflicts in the same state requires further interrogation, but is beyond the scope of this paper.
} 
drives this re-direction and how does it impact affected-population vulnerabilities? These are questions that focus on the role of the humanitarian system in exacerbating the challenges faced by divided disaster-affected populations, and will therefore offer a new way of looking at certain conflict-disaster linkages.

To explore this point, the paper will build on emerging research around organisational agenda-setting in the international humanitarian system and will look at how dominant norms especially framings of 'humanitarian effectiveness' (Fiori et al, 2016) - determine the wider parameters of a response when crises occur simultaneously. It will argue that dominant 'humanitarian effectiveness agenda' has created perverse incentives for agenda-setting, which have not only pushed international humanitarian organisations to compete against each other in the 'humanitarian marketplace' for funds (Cooley and Ron, 2002), but which have also pitted humanitarian crises against each other in terms of whether they can improve an organisation's "reach", "visibility" and "impact" (Fiori et al, 2016; Kapoor, 2007). In distanced conflict and disaster emergencies occurring in the same state, this essentially pits the conflict against the disaster, with potentially significant effects on the vulnerabilities of affected and interconnected communities on either side.

The paper will begin by contextualising the development of the humanitarian effectiveness agenda in order to construct a lens through which to analyse divided disasters. To do so it will draw on literature that bridges humanitarian studies and organisational analysis (for example: Krause, 2014; Fiori et al, 2016; Orgad, 2012; Wong, 2012; Natsios, 2010; Ferguson, 1990). More specifically, it will build on the recent work of Krause (2014), who has examined what shapes 'the good project' in head-office imaginations of a crisis, and Fiori et al (2016), who examine the influence of neomanagerialism and business sector principles on humanitarian agenda-setting. These scholars, which include myself, argue that: humanitarian effectiveness has increasingly become equated with efficiency, particularly cost-efficiency; interventions are driven by donor imperatives to show value for money; there is a diminishing engagement with the politics of a crisis; and competition for funding has resulted in the prioritisation of risk-aversion in complex emergencies (Krause, 2014; Fiori et al, 2016; Field 2017; Natsios, 2010; Valters and Whitty, 2017). A consequence of these developments has been an encouragement of projects that are easy to sell (to donors or tax-payers) and easy to measure (enabling a show of success).

Once the frame has been set, the paper will use it to briefly analyse conflict-disaster contexts where these two crises are intersecting in the same space: Sri Lanka and Indonesia (Aceh) after the 2004 Indian Ocean Tsunami (Hyndman, 2011; Zeccola, 2011; Waizenegger and Hyndman, 
2010; Le Billon and Waizenegger, 2007). Here I will (re)articulate arguments as to how organisational priorities - including response visibility and donor accountability (central to 'the good project' and the humanitarian effectiveness agenda) - led to a sidelining of protection programming for conflictaffected populations in favour of relief for those impacted by the tsunami. The aim of this second section of the paper is to raise a set of questions pertinent for the third, including: if we can see clear asymmetrical priority setting in a context where disasters and conflict geographically collide, what are the implications of when they occur simultaneously but not in the same location? What are the additional effects of that distance?

The third section of this paper will then tease out the implications of these questions by analysing the case study of the Philippines following conflict-induced displacement in Mindanao in September 2013 and Typhoon Haiyan in November 2013. ${ }^{3}$ In particular, it will examine the extent to which the humanitarian response to the typhoon drew resources (financial and human) away from Mindanao based on dominant understandings of effectiveness, and what the implications of that diversion might have been for protection and human security in the conflict-affected area. This will offer a new set of questions for the scholarly debate around the conflict-disaster nexus, as it will highlight the need to consider vulnerability beyond the proximate conflict-disaster crisis/crises, and look at the impact humanitarian responses have on exacerbating crises elsewhere through the resource (re)allocation that comes in pursuit of 'the good project'.

\section{Methodology}

As part of Save the Children UK and the University of Manchester's Humanitarian Effectiveness Project (Fiori et al, 2016; Espada, 2016) I undertook field research in the Philippines between January-February 2015 and was exploring understandings of humanitarian effectiveness in response to Typhoon Haiyan. Interviews were conducted in Manila (the capital), Tacloban (in the Eastern Visayas region, one of the worst-hit areas of Typhoon Haiyan) and Ormoc (a city also in the Eastern Visayas and badly hit by the typhoon). Interview participation included four village community group discussions, two focus-group discussions with international on-governmental organisation (INGO) workers in-country, and forty-five individual/small group interviews with foreign aid workers, Filipino aid workers, local government officials, academics based the University of the Philippines, and a range of individuals affected by the typhoon (see: Field, 2016; Field, 2017). The second phase of this research has been examining the relation of Typhoon Haiyan to the spike in conflict in Mindanao in 2013, and was initially sparked by interviewees for the above project discussing the

\footnotetext{
${ }^{3}$ The 2013 emergency situation in Zamboanga and Basilan, in the Mindanao region, will be explored in more detail shortly. This crisis arose as a result of violent confrontation between forces of the Government of the Philippines and an armed separatist group.
} 
situation in Zamboanga and Basilan in light of Typhoon Haiyan. To inform the analysis in addition to interviews, I undertook a substantial desk review of the Office of the Coordination of Humanitarian Affairs (OCHA) and INGO situation reports, policy documents and organisational analyses relating to the Zamboanga and Basilan conflict, published between September 2013 and December 2014.

\section{The Humanitarian Effectiveness Agenda and the search for 'The Good Project'}

'Some recipients are easier to help than others, and those who are hardest to help often receive no help at all'. (Krause 2014: 41)

Humanitarian agencies have long been subject to, and have shaped in turn, modern organizational imperatives. These include: professionalisation for improved efficiency, competition for funding, bureaucratisation, marketing for enhanced visibility, supply chain management for logistical effectiveness, and so on (Fiori et al, 2016; Cooley and Ron, 2002; Lindenberg, 2001; Orgad, 2016; Wakolbinger and Toyasaki, 2014). Analysing such trends, a growing body of literature has subsequently begun to tease out ways in which these structures, systems and working cultures are not just affecting management at headquarters, but are also shaping and determining policy and programming decisions in the field (Wong, 2012; Hopgood, 2013). For instance, in Monika Krause's book The Good Project, she outlines a schema of organisational concerns that influence how Western aid agencies determine where and how they intervene (2014: Chapter 2). Needs, she explains, are often not enough to determine the selection of a project, as there are other aspects that direct humanitarian action. Risk-management features as an important concern - both in terms of whether there is a security risk for staff deployed to the context and also in terms of whether there is a reputational risk in being seen to be focused too much on one issue/location (Krause 2014: 35), or perhaps being viewed as ineffective or exacerbating the crisis. Political factors at a national level have to be taken into account, too (Wong, 2012: 3). Donor interests in a certain state or crisis can direct international focus to some emergencies over others (Krause 2014: 34). So too can the expectation of access denial by affected-country governments (Zeccola 2011: 311). Related to the above, Krause found that - unanimously among all of the humanitarian managers she interviewed a key concern was 'making a contribution' or 'adding value' (Krause, 2014: 35). Here, she explains, resources are important - especially money. 'Resources depend on donors' priorities and media attention'. But added value also depends on 'the more mundane logistical issues that arise in the planning of projects' (Krause 2014: 36), such as ensuring access and free movement across the territory. 
All these considerations - risk, politics, adding value - sit behind programme decisionmaking because modern relief agencies are overwhelmingly concerned with producing what she terms as 'the good project'. The good project has become the core organising principle and the primary means of helping people because 'it lends coherence to what are otherwise quite disparate activities' - activities such as data collection, recruitment, fundraising, booking planes and undertaking vulnerability assessments (Krause 2014: 28-30). Its discreet and time-bound nature also lends itself to the formation of measurable indicators for monitoring and evaluation, which are the means of demonstrating effectiveness in relation to predetermined goals. And, of course, demonstrations of effectiveness in current/past projects are essential for securing future funds. Measurability and the demonstration of success against predetermined goals have thus become core facets of the humanitarian effectiveness agenda, and they continue to drive momentum for the projectisation of aid.

Ideas of what constitutes 'success' are inevitably filtered through an agency's understanding of its mandate - for example, whether it is a health-focused agency, child-focused agency, development-focused as opposed to humanitarian, and so on. But ideas of 'success' are also affected by broader economic and political norms around what constitutes effective aid in the first place. A classic example is James Ferguson's (1990) analysis of the "Bovine Mystique" rationale in southern African development management in the late 1980s. Ferguson (1990: Chapter 5) examined how aid managers' economistic views on the problems of cattle over-grazing and poverty in Lesotho led them to introduce improved livestock/range management programmes: a cash-focused market for the sale of cattle, new cattle breeds, and land privatisation. Their ideas of 'success' were marketdriven and economistic (to improve immediate market access and cash flow among the communities), which, Ferguson (1990) explained, did not match the priorities of the farmers' families, for whom cattle were a long-term investment for retirement or in case of difficult times cattle did not need to be immediately fungible. Ultimately, however, it did not matter how the farmers and their families viewed the value of the cattle, as the aid managers had already predetermined that effectiveness required a working market and cash flow, and programme planning worked back from there. In doing so they took a political decision around the socio-economic organisation of the community (what the cattle is for) and re-framed it as simply a technical issue (not enough cash-flow), requiring an immediate technical solution (a market) (Ferguson, 1990: 87).

This frame and type of project was not (and still is not) unique in both development and humanitarianism, and these economistic, market-centred norms that underline 'success' have come to be taken for granted as effective aid (Easterly, 2014; Natsios, 2010; Etherington, 1996: 7; 
Leftwich, 1993). Yet, these norms are not 'objectively' effective, and their organising logics have a particular political genealogy.

A revolution in public sector management in the United Kingdom and United States in the 1970s and 1980s - famously driven from the top by UK Prime Minister Margaret Thatcher and US President Ronald Reagan - embedded business principles in public sector bureaucracies (Borins 1995; Newland, 2001; Fiori et al, 2016). These neo-managerial principles included the imperatives of 'doing more for less', ensuring value for money for any government initiatives, undertaking results-based management to measure success, and underlining the importance of technical expertise.

Competition and incentives sat at the heart of this agenda - coined New Public Management (NPM) (Borins, 1995) - and the driving idea was to 'liberat[e] managers from regulation by central authorities' (Fiori at el 2016: 30). Public relations became a key ingredient for success under this new regime, as tax-payers and service-users became increasingly treated as customers and consumers. It was an ideology concerned with the 'depoliticisation' and 'economicisation' of institutional life (Fiori et al 2016: 30; Pollit, 1990; Gorz, 1989).

Such principles rapidly became organising doctrines for the aid sector, primarily as a result of two historic developments. Firstly, through the professionalisation of aid work across the late twentieth century, which saw many government officials, career civil servants, technocrats and technical experts transfer to the aid sector undertake humanitarian and development work as part of their career trajectory (Hilton et al, 2014: 7). With them they brought their management structures and theories of organisational best practice (Hilton et al, 2014; Fiori et al 2016). Secondly, through the top-down financial governance of humanitarian aid, as governments became the main donors for humanitarian action, seeking a soft-foreign policy engagement tool following the end of Cold War power-bloc politics (Barnett 2009:630).

As the 1990s saw a rapid growth of expenditure in the humanitarian sector - principally by OECD DAC (Organisation for Co-operation and Development, Development Assistance Committee) countries who were growing their aid budgets - public accountability of these donors to their domestic constituencies demanded a focus on the (cost) effectiveness of such large budget allocations. In other words, that there had to be a value for tax-payers' money in the assistance (Borton, 2009). Evaluations of 'effectiveness' became increasingly infused with concerns over budget and spending efficiency, which were not only underwritten by an accountability 'upwards' towards donors and their tax-paying constituencies, but - due to the secondary nature of evaluations as learning documents - offered lessons learned for future activity-planning stages too. This creates a 
feedback loop of reinforcement in which cost efficiency (getting the most impact for the money given) remained a key concern of overall intervention effectiveness.

Moreover, the professionalisation of the sector and the increased funding available for relief agencies to undertake humanitarian and development work created an aid market. This market, argue Cooley and Ron (2002: 8) has adopted all the characteristics of a commercial market, inciting inter-agency competition and what they refer to as 'the NGO scramble' - a struggle for funds, visibility, and opportunities to expand their mandate. And this is having 'dysfunction[al effects] beyond coordination failure... including disincentives to protest aid diversion and empowerment of uncooperative aid recipients' (Cooley and Ron 2002: 13). It can discourage organisations from undertaking humanitarian operations that are 'high risk', either in terms of physical security, or in terms of the extent to which agencies would be able to attain their goals (Fiori et al, 2016; Krause 2014). This humanitarian effectiveness agenda, and focus on producing 'the good project', can also create perverse incentives to 'help those who are easiest to help', or to focus primarily on measurable material factors on the ground, such as numbers reached (Krause 2014: 38). These effects are particularly evident in crises where there are conflict and natural-hazard induced emergencies occurring in the same location. Aid money and resources can be drawn to the latter at the expense of the former, because natural-hazard induced disasters often - in the short term at least - present lower risk interventions for aid workers, higher visibility in the media, and have an ostensibly 'less complicated' narrative for fundraising than conflict situations among other reasons (Zeccola 2011: 317; Waizenegger and Hyndman 2010; Hyndman 2011). The following section will explore these points through an analysis of the conflict-disaster nexus in Sri Lanka and Indonesia.

\section{The Conflict-Disaster Nexus: Proximate Crises}

The 2004 Indian Ocean tsunami killed 225,000 people and displaced over 1.8 million, mainly across South and Southeast Asia. The international response to the disaster was the largest up to that point, with donated funds surpassing the previous largest (Hurricane Mitch in the US) by twenty times - US\$14 billion was raised for relief and reconstruction, $\$ 6$ billion of which came from private donors (Hilhorst and Jansen, 2013: 194). However, the humanitarian crisis in this region was not restricted to the tsunami. Aceh in Indonesia - one of the hardest hit areas by the tsunami - and Sri Lanka, also severely affected, had long-running internal conflicts in areas that overlapped with the tsunami-affected zones. Aceh had been the site of an insurgency movement since 1976, and Sri Lanka since 1983 (Hyndman, 2009: 90). 
As noted above, in conflict-disaster contexts where a hazard and a conflict intersect in broadly the same space, analysis has shown that there is often a bifurcation of attention and a tussle for funding commitments, with protection programmes for conflict victims often losing out to relief for those affected by disasters (Zeccola 2011: 317; Waizenegger and Hyndman 2010; Hyndman 2011). In Aceh, for instance, Waizenegger and Hyndman (2010: 787) noted that there were 'very separate flows of aid' to the 'dual disasters' of the war and the tsunami, with the majority of the resources directed towards tsunami-affected populations living on the coast. Zeccola (2011:315316), too noted that 'it was clear that foreign assistance was welcome in the response to the tsunami, but it was most unwelcome in response to the conflict'. Part of this, Zeccola (2011: 316) explains, was a result of the immense scale of the disaster, which saw NGOs 'naturally' throw themselves into life-saving relief mode. Other shifts came more reluctantly, as some NGOs attempted to balance conflict and tsunami-related programmes simultaneously but had to close the former as demand for tsunami-related support increased (Zeccola, 2011: 317).

In Sri Lanka, agency staff that had extensive experience working on the conflict in the region 'were pushed aside by strangers... on account of the latter being specialists in humanitarian emergencies' (Hilhorst and Jansen 2013: 196). The significant value of the funds being channeled into the response resulted in fierce competition over staff, territory, and beneficiaries (Stirrat 2006: 13). And the subsequent need to account for these funds to the donors (i.e. to demonstrate the success of 'the good project') resulted in organisations seeking out opportunities for visibility namely, photogenic moments with the poor, women, and children (Stirrat 2006: 13). The Tsunami Evaluation Coalition (TEC), convened in 2005 to coordinate evaluations of the overall tsunami response, criticised this rivalry stating that 'the perceived need for quick, tangible, agency-specific results fuelled competition for visibility, "beneficiaries" and "projects"' (Telford and Cosgrove 2006: 22).

Organisational competition and territoriality over aid recipients and operating areas are key facets of the humanitarian effectiveness agenda, as projects are driven by opportunities for visibility and the ability to measure results. Increased donor attention on disaster responses have encouraged agencies to 'expand their influence... [and] project their competitive advantage through narratives of success' (Fiori et al, 2016:44). The consequences of such an approach, in a "dual disaster" scenario, can be diversion and the exacerbation of the vulnerability of already vulnerable communities. Kennedy et al (2008: 30) noted that 'In Sri Lanka beneficiaries were selected on the basis of being verifiably tsunami-affected, so conflict affected people were immediately left out. In Aceh, lack of 
support for conflict-affected people became a contributing factor to security issues for some NGOs trying to address only the tsunami-affected population'.

Furthermore, this distinction in programming is reinforced through a feedback loop of evaluations that measure success based on original programme goals rather than their impact on the larger aid eco-system and 'peripheral' communities (Fiori et al, 2016: 44). In this case, tsunami programme evaluations measured success in their assistance of tsunami-affected populations rather than those impacted by conflict. Even the TEC stated that it did not explicitly address 'the question of how the tsunami and the aid influenced the conflicts in Sri Lanka and Asia' (Telford and Cosgrove, 2006:28).

This raises an important question about other, lesser-analysed (but no less significant) scenarios: if we can see clear asymmetrical priority setting in a context where disasters and conflict geographically collide, what about when they occur simultaneously but not in the same location? To what extent do the perverse incentives created by the humanitarian effectiveness agenda impact crises and programmes beyond the limits of the headlining emergency? To explore these questions in more detail, the paper will now turn to a case study analysis of the Philippines, which experienced the divided disasters of Typhoon Haiyan and conflict in Zamboanga and Basilan in 2013.

\section{Philippines: Conflict Context}

The Philippines has been experiencing internal conflict since the late 1960s. Fighting is broadly confined to the southern part of the country, particularly the remote islands of central Mindanao. As well as a communist insurgency led by the New People's Army (NPA), the country has three dominant Muslim separatist groups: the Moro National Liberation Front (MNLF), the Moro Islamic Liberation Front (MILF), and the Abu Sayyaf Group (ASG), the latter two of which are factions that broke away from the MNLF. Direct confrontation of the various militant groups with the government has peaked and troughed over the five decades, and has been exacerbated by agrarian modernisation and conflict over natural resources (Vellema et al, 2011). Relevant for this analysis is the spike in violence that occurred in 2013.

On the $9^{\text {th }}$ September of that year a section of the MNLF marched on the Mindanao city of Zamboanga and attempted to raise the flag of the self-proclaimed Bangsamoro Republik at Zamboanga City Hall. This military action was met by both the Armed Forces of the Philippines and the Philippine National Police, and the ensuing battles in Zamboanga and Basilan resulted in the displacement of more than 119,000 people with several civilians killed in the fighting (OCHA, 19 Sept 
2013). Many of the IDPs (internally displaced persons) were forced to live in overcrowded evacuation centres with incredibly poor water and sanitation conditions. In one centre, there was reportedly only one toilet per 1,500 inhabitants (OCHA, 26 Sept 2013). Around 47 people died between September and mid-December due to poor hygiene conditions (OCHA 3 Jan 2014). This situation was compounded in October 2013 when heavy rains caused flooding throughout Zamboanga, submerging some of the evacuation centres and increasing the risks for many living in them (OCHA, 3 Jan 2014).

The emergency management for this response was kept largely at a national and local level. The Filipino Government's Department of Social Welfare and Development (DSWD) took the primary lead, along with the City Government of Zamboanga. Some support was provided through members of the Humanitarian Country Team and Mindanao Humanitarian Team of the UN Office for the Coordination of Humanitarian Affairs (OCHA). However, there was no formal request for international assistance by the Government of the Philippines (GoP), and offers reiterated for this to GoP's National Disaster Risk Reduction and Management Council (NDRRMC) by the UN Humanitarian Coordinator in the Philippines were not taken up (OCHA 23 Sept 2013).

By January 2014, some 63,000 were still displaced. Sixty-nine per cent of children were still out of school, and there were 'key challenges remain[ing] in terms of food, nutrition, water, sanitation and hygiene (WASH), health, education, protection and livelihoods' (OCHA 14 January 2014). Nonetheless, in December 2013 government food distributions virtually ceased as they aimed to transition towards recovery-mode and 'food for work' initiatives. Despite this apparent signaling of the end to the emergency phase, the response continued to struggle and IDPs remained in precarious shelters. By mid-January 2014, US\$6.8 million had been contributed to the Zamboanga and Basilan Action Plan, but financial needs remained over 70\% unmet, which limited humanitarian programming in all the intervention areas (OCHA 14 Jan 2014). Sitreps (situation reports) issued by OCHA between September 2013 and January 2014 speak of a crisis in human resources, repeating week-on-week that there was a shortage of medical workers and protection officers, as well as a significant training needs-gap for government officers and local organisations working across all of the main humanitarian programming sectors. In a key informant interview, an OCHA official explained that, by mid-2014, the limitations in the response were 'prolonging a humanitarian emergency' (Interview, January 2015).

In terms of what was exacerbating this ineffectiveness and protection gap, shortfalls in funding certainly curtailed the possibilities of the response. As a senior manager of one of the country's largest INGOs explained, 'Zamboanga was grossly underfunded. [Our organisation] had to pull out'. 
This is not something unique to Zamboanga, as raising humanitarian funding for a spike in violence in a protracted conflict situation can be difficult - particularly for private donor-funded charities because humanitarian fundraising frames rely heavily on decontextualized images of 'innocent victims' to mobilise and monetise sympathy (Walton, 2017; Darnton and Kirk 2011). Protracted warfare and internal conflict can be seen by private donors (indeed also tax-payers who contribute to government aid funds) as 'too complex', with aid potentially being diverted to 'less-deserving' beneficiaries who are complicit in the violence (Bennett and Kottasz, 2000: 358). This is in contrast to, for example, large scale natural hazard-based disasters, where causality in media narratives can be simplified to a rapid-onset meteorological/seismological explanation, and those affected appear innocent of blame and/or not 'too distant' for the Western donating public to empathise with (whether proximity comes geographically or in terms of identity, because some/many of the victims are Western) (Moeller, 2006).

Funding from the international humanitarian community was further limited in the case of the Zamboanga and Basilan crisis by the fact that the GoP did not open out a call for international assistance. While money was made available to the national response through the UN's Central Emergency Response Fund (CERF) and bilateral donations, the UN and INGOs were to take a back seat in coordination and programming. As the foreign coordinator of the humanitarian hub in the city noted, when he arrived in May 2014, he was the 'only international aid worker left in Zamboanga' and the response was mainly being directed by a small number of local organisations (OCHA 20 April 2015). While not a problem for humanitarian operations in terms of skills and experience - as the Philippines has a strong history of local Civil Society Organisations (CSOs) and Red Cross chapters working in disaster response (Heijmans 2009; Field 2017) - the lack of international presence limits wider attention and proscribes international fundraising campaigns, potentially exacerbating the limited pool of funds. This is a subject to which I will return shortly.

Nevertheless, a funding shortfall cannot be taken as a standalone explanation, nor can it be taken in isolation of wider factors. To understand why there were such chronic weaknesses in the Zamboanga response, it is necessary to place the crisis management situation of Zamboanga in the wider context of national disaster management in the final quarter of 2013 , and in relation to the organising logic of humanitarianism much more broadly.

\section{The Conflict-Disaster Nexus: Distant Crises}


Within a few months of the initial siege in September 2013, the country experienced the Bohol earthquake, which occurred on the 15 October in the Central Visayas region killing over 200 people. It was felt as far as Mindanao, but with no fatalities in that region. The earthquake resulted in significant displacement with over 79,000 houses damaged, 13,402 of them completely destroyed (ReliefWeb, 2013). Less than a month later, on 8 November 2013, the Philippines then experienced one of the strongest typhoons to make landfall in the country, Typhoon Haiyan (known locally as Yolanda). Haiyan devastated a substantial part of the Visayas region killing over 6,000 people, displacing 4.1 million and affecting a total of 14.1 million (OCHA, 16 Dec 2013). For both Bohol and Haiyan, the Government of the Philippines (GoP) called for international assistance and requests of funds were US\$33.8m USD and \$775.7m USD, respectively. By April 2014 the Bohol Flash Appeal was 49\% met (FTS n.d.[a]). By October 2014, 60.5\% of the Haiyan appeal funds were met (FTS n.d.[b]). Zamboanga, Bohol and Haiyan were a formidable triple-disaster to hit a single country over the space of just a couple of months.

On the international and national level, there was a huge surge of assistance following the declaration of Typhoon Haiyan as a Level 3 (L3) disaster. The L3 declaration by the Emergency Relief Coordinator marked it as the highest level of humanitarian crisis, and it became the first large-scale relief effort for a sudden-onset disaster since the adoption of the Inter-Agency Standing Committee protocols under the 2005 Transformative Agenda. The inter-agency surge that accompanied the declaration saw hundreds of international staff deployed to the Philippines within the first three weeks (Interview, January 2015). It appeared to be, to borrow Hilhorst and Jansen's (2013:196) phrase concerning the 2004 Indian Ocean Tsunami, 'everybody's disaster'. Just as in the Indian Ocean region in 2004, INGOs, national NGOs, private organisations, faith-based organisations, tourists and other private individuals arrived at the most devastated areas and established varying forms of "relief operations". A study by Saben (2015: 1503) calculated that the response involved a total of 515 organisations, 178 of which were international.

Deployments and were not just international. Human resources were drawn, too, from elsewhere in the Phillippines, including Bohol, ${ }^{4}$ Zamboanga and the wider Mindanao region. An OCHA sitrep for the Zamboanga and Basilan Emergency notes in December 2013 that 'the logistics capacity is overstretched due to multiple emergencies ongoing in the country' (OCHA 23 Dec 2013). This was confirmed in a key informant interview (January, 2015) with a UN official deployed there in

\footnotetext{
${ }^{4}$ The effects of the Haiyan response to programmes focusing on the Bohol earthquake are beyond the remit of this paper. This paper will primarily focus on the crises of Zamboanga and Haiyan as it builds on field data that specifically notes the redistribution of resources around these two events, and the paper is primarily concerned with constructing an initial argument around divided disasters across separate, but connected, geographies. Further research must be done to build upon these ideas through bringing in the Bohol earthquake response as a third competing emergency.
} 
2014, who described a situation of threadbare resources. Refugees International stated in December 2014 that part of the reason tens of thousands remained displaced around Zamboanga City a year on was because 'the enormity of the disaster Haiyan left in its wake pulled attention and resources away from the humanitarian needs of IDPs' (Thomas, 2014). Dara McLeod, then-Communications Director of Refugees International, posted on Twitter a year on from the crisis: 'Humanitarians in Philippines focused on Haiyan response, as IDPs in Zamboanga suffered - and still suffer' (Twitter, @mcleoddk 18 November 2014).

Moreover, this redeployment did not just involve aid workers who had been in the conflictaffected southern island of Mindanao since the September siege, but some that had been working on relief and rehabilitation programmes there for much longer. One manager in the Philippines Red Cross noted that they were quick to respond to the Typhoon and 'most chapters that came here were from Mindanao and Luzon ... Those coming from Mindanao had experienced [Typhoon] Bopha', which was the strongest typhoon to ever hit the southern island, making landfall in December 2012 (Interview, February 2015). Another key informant that worked for the Philippines Red Cross at the time reflected, 'A key tension that is difficult to balance is that, in an emergency situation in the Philippines for example, staff are called on from across the organisation to assist in the crisis-hit area. However, many of these were based in other ... offices to work on long-term development projects' (Interview, January 2015). While it is difficult to ascertain exact numbers of those redeployed across programmes, as this was not systematically recorded across agencies, interviews with local and international aid workers during research on the response to Typhoon Haiyan suggest a significant level of staff rotation.

Meanwhile in Zamboanga, more than a year after the crisis, around 38,000 remained displaced, which was almost 14,000 more than were still displaced from Haiyan at the time (OCHA, 2014). More than 20,000 of those Zamboanga IDPs were living in overcrowded evacuation centres. Conditions remained poor, as the IDPs had limited access to safe water, sanitation and hygiene, and 'alarmingly low health and nutrition conditions' (Thomas, 2014). These poor protection indicators a year on from the crisis are, I argue, partly due to issues of scale and the way that the prevailing aid system (re)prioritises crisis responses as a result of dominant understandings of effectiveness.

\section{Typhoon Haiyan as 'the good project'}

In terms of 'adding value', as noted above, many aid workers were redeployed from other programmes within the country, including the Zamboanga response, because there was a framed 
(more) urgent need in Haiyan-hit areas due to the scale of the disaster. This was creating programme shortages elsewhere and a revolving door of staff movements. One Manila-based INGO manager noted (Interview, February 2015) that, 'among the NGOs based here, much poaching happened' as staff were headhunted from competitor organisations and other projects to fill gaps as Haiyan projects expanded. Filipino aid workers were sought (rather than foreigners recruited from international projects) because of language skills and the significant experience that many Filipino aid workers have in humanitarian and development programming.

Moreover, just as with the Indian Ocean Tsunami of 2004, many of these aid programmes and recruitment operations were driven by funding and the mandates that came with those grants. The INGO that had to pull out of the Zamboanga crisis because it was 'grossly underfunded' remarked that they also experienced 'high grant infusion' for the Haiyan response, which gave them 'the luxury of building substantial capacity [for Haiyan]' (Interview, January 2015). These managers admitted that it was not always untied funding, but it was still exclusively for the typhoon response: 'we were boxed-in by international fundraising. [Our] hands were tied due to the awards... [R]ecruitment was driven by a grants mindset. These grants were often short and focused on specific [Haiyan-related] activities'.

Media attention to the typhoon drove much of this 'high grant infusion', as the global media sought high-emotion stories to reach their audiences. As Ong (2015: 8) explains:

This representation of suffering at its worst in global media was successful in drawing worldwide attention and help with humanitarian fundraising. My interview with an official of the UK's Disasters Emergency Committee reported that their Haiyan appeal was among their most successful fundraising initiatives for a natural disaster.

And the result was somewhat of an aid circus in the typhoon-affected areas. As well as Western journalists 'parachuting' in for stories of suffering (Ong 2015:8), hundreds of aid agencies were to be found working in the same spaces and attempting to brand their territory. One aid worker from an INGO sub-office noted that, 'You plan an activity to go into an area and you discover another agency' (Interview, February 2015). Another - a senior manager of a CSO - recalled that there was much 'duplication of geography' as aid agencies worked in the same villages (Interview, February 2015). A local INGO worker based in Ormoc recalled that so much of the aid work occurred in the easy-toreach areas along the highway - particularly in Tacloban, which was one of the hardest-hit areas and 
therefore received the most attention and funding. In Manila, an INGO manager explained this as 'a battle for media visibility... many organisations capitalise[d] on the visibility of the event'. Ilan Kapoor (2007: 106) describes this surge of aid focus on a high-profile crisis as the 'imperative to act and to act now', which has emerged from the public relations opportunities that emergencies provide for NGOs to legitimise their functions and expand their operations.

Overall what these interviews suggest was that there was a strong need to be seen to be 'doing something' in relation to Haiyan, and human and financial resources were being directed away from other crises in the Philippines as a result. This was not with any overt desire to detrimentally affect programming elsewhere, but because - as per the humanitarian effectiveness agenda - competition for funding has resulted in the prioritisation of scale (i.e. numbers affected) and visibility (Fiori et al, 2016; Natsios, 2010; Cooley and Ron 2002:16 [fn.44]). ${ }^{5}$

This resonates with observations of the post-Tsunami responses in 2004. As Stirrat (2006:16) noted ' $r$ ]elief agencies were very conscious of existing in a highly competitive world and in the long term saw themselves as competitors for resources'. Importantly, he explains, this competition was not to raise resources, but to spend them - and there was such a 'high grant infusion' from donors (to borrow a phrase from the key informant above) for the tsunami response that competition focused around area of operation and control of beneficiaries (Stirrat 2006:16). However, as previously noted, this spending could not be on anyone and aid agencies were reluctant to jeopardise their tsunami funding by working with conflict-affected victims (Zeccola 2011:232).

While there were echoes of this problematic post-tsunami division - or 'solitudes' (Waizenegger and Hyndman, 2010; Hyndman 2011) - of aid in the Philippines in 2013, the difference was that the separation of geography between Haiyan and Zamboanga-affected areas meant that the impact and implications of an asymmetrical and diverted response have been almost entirely overlooked. In other words, the potential exacerbation of the protection gap in Zamboanga and the widening of aid-inequality between those in the conflict-affected areas and those in the rest of the country affected by the typhoon, have not been discussed as interconnected and potentially coconstituted crises.

In some ways, the Zamboanga emergency was even seen as an enabler of the expansive typhoon response, underlining the hierarchy of scale in the humanitarian system. For instance, the

\footnotetext{
${ }^{5}$ Risk-mitigation might also have factored into these decisions. Zamboanga is a high-risk context for aid organisations, as Mindanao has long been a site of aid worker kidnappings by extremist organisations and therefore a high-risk situation for aid worker deployment. For example, in 1999 a Belgian aid worker was held hostage for ten days by ASG (UPI, June 23 1999). In 2008 two local aid workers from the Nagdilaab Foundation and Office of the Presidential Adviser to the Peace Process were abducted, again by ASG (GMA News, Sept 18, 2008). Less than a year later the extremist organisation kidnapped three more aid workers, an Italian national, a Swiss National and a Filipino who worked for the International Committee of the Red Cross (ABS CNN 31 March 2009).
} 
IASC Inter-Agency Humanitarian Evaluation of the Typhoon Haiyan Response states that 'a number of characteristics of the Philippines created highly favourable conditions for an effective disaster response'. These included 'the absence of a high profile "competing" disaster at that time', and 'the ability of in-country humanitarian teams (international and national) to redeploy from existing emergences in Mindanao and Bohol' (Hanley et al 2014: 18, 67). Arguably, the framing of competition here acknowledges the fact that the humanitarian sector does not have unlimited capacity and additional resources to meet the scale of typhoon Haiyan must come from somewhere. However, multi-mandate INGOs and intergovernmental organisations do not just have a responsibility to go where there are higher numbers of affected people. As well as remaining in complex emergency situations to address the material needs of conflict-affected communities, there is a broad academic and policy acceptance of their responsibility to also undertake advocacy and to challenge dominant discourses about conflict, or build public understandings of complex humanitarian issues, above and beyond the relief scenario (Walton 2017: 4).

This did not happen in 2004 after the tsunami, and academics have subsequently critiqued the impact of the apolitical and tsunami-focused approach to the dual disasters as damaging to peace building and conflict transformation at a regional level (Zeccola 2011; Waizenegger and Hyndman 2010), and as exacerbating the loss of human security for individuals and communities on the ground (Hyndman 2014:111). Given that such apolitical and disaster-focused programming continued in the Philippines in 2013, there seems to be a need, therefore, to begin to theorise as to the impact of 'the good project' (i.e. the Haiyan response) on human security in Zamboanga and Basilan.

\section{The politics of divided disasters in the Philippines}

As noted previously, the GoP declined to call for international assistance with the Zamboanga and Basilan emergency, instead preferring to manage it through the DSWD and the city authorities. They activated their own government-led cluster system in the early phases of the response, but then declared the humanitarian phase over in August 2014, despite 38,000 people still being displaced (OCHA 2014a) and the under age-5 mortality emergency threshold being breached six times since September 2013 (OCHA 2014b). The UN key informant official based in Zamboanga over 2014 shared his personal understanding of the government's motivation:

In Mindanao, the government doesn't want any intervention. ... There was a human need justification for Haiyan, but it was a protection issue with 
Zamboanga... The humanitarian situation was not due to the conflict, it was due to the government dragging their feet and not resettling. Mindanao requires a political solution'.

The protection issues and low human security in Zamboanga, and Mindanao more widely, have certainly been an issue for many decades. The absence of state services in the region has exacerbated the population's vulnerability long before the crisis (OCHA 2013). Strachan (2015: 20) reports that the majority of barangays (village units) in the southern island continue to lack access to civil registry institutions and the justice system, which is limiting their ability to claim rights. Moreover, the region has the 'worst health governance statistics in the Philippines' (Strachan 2015: 20). Chronic poverty is seen to be both a result and a cause of the violence that has been ongoing since the 1970s (Malapit et al, 2003).

After the Zamboanga conflict, many of these protection issues, and the tension between the GoP and the local population, were manifest. For instance, there was evidence that IDPs were having their stay in the emergency evacuation centres unduly prolonged. The Internal Displacement Monitoring Centre (IDMC) noted in October 2014 that the displacement situation remained dire with over half of those still displaced unable to be resettled because they were in "no return" areas or it was unclear whether they were eligible for resettlement (IDMC 2014: 5). They explain that the City Government of Zamboanga did not consider many of those living in the IDP evacuation centres as 'legitimate' IDPs from the conflict, but opportunity-seekers wanting to take advantage of the housing assistance (IDMC 2014: 5). However, citing a UNHCR analysis from 2014, IDMC refuted the claim, arguing that an overwhelming majority of the IDPs had been living in Zamboanga for a long time and had been displaced by the conflict (IDMC 2014: 5).

Concerns over state legitimacy in relief and rehabilitation in the conflict zones of the Philippines are certainly nothing new (Soriano 2006:8), and are beyond the scope of this analysis. The purpose of illustrating these concerns around the politics of relief and resettlement in Zamboanga are to question the extent to which these can be considered in conventional humanitarian effectiveness frames and the search for 'the good project' when several emergencies are vying for resources. Given the chronic protection and human security deficit in Zamboanga, was there an additional obligation for international aid organisations not to redeploy humanitarian resources from the context, even with a simultaneous disaster the size of Haiyan? It is an open question and one focused on reimagining effectiveness beyond competitions of scale, visibility, and value for money. That is not to say international aid organisations would automatically offer more enhanced 
protection and more effective humanitarian assistance than, say, local CSOs and NGOs. Rather, it is to argue that a less competitive humanitarianism could help prevent or mitigate some of the problems that come with the diversion of attention and resources, including the political problems of the interpersonal relations between state institutions and the conflict-affected Mindanao communities.

\section{Conclusion}

This paper has examined key ideological norms of the dominant humanitarian system that inform decision-making over where to direct resources in the event of multiple, simultaneous crises. It has highlighted a culture of competition that has emerged as a result of the ascendancy of the humanitarian effectiveness agenda - informed by the NPM norms of the 1990s - and the search for 'the good project'. Agency concerns over visibility in high profile crises, accountability upwards to donors, and impact-through-numbers-reached are reinforcing the idea of the aid sector as a marketplace. This has particular consequences for the conflict-disaster nexus with, apparently more 'complex', crises such as conflict being forced to compete with the more 'pure' humanitarian crisis of a 'natural' disaster. I have built on established academic critique by arguing how the humanitarian effectiveness agenda contributed to creating 'disaster solitudes' in Aceh and Sri Lanka in 2004, as significant resources were directed at tsunami-affected communities, often at the expense of those affected by chronic conflict. This analysis has provided a fruitful foundation for beginning to explore the impact of the humanitarian effectiveness agenda on the conflict-disaster nexus for divided disasters - geographically distinct crises occurring within the same national boundaries. There was a clear redeployment of resources from smaller scale emergencies in the Philippines to the Haiyan response, and this has implications for the ability of the former to meet the needs and aspirations of the affected populations. The emergency in Zamboanga was not a one-off humanitarian crisis, but part of a longer history of violence in a situation of chronic poverty, insurgency and state conflict. However, the ascendance of a neo-managerial aid culture characterised by technical inputs and measurable goals has entrenched technocracy and competition for results in the humanitarian system, and a rejection of engagement with politics and governance (Fiori et al 2016:69). This, at the international response level at least, resulted in the Zamboanga assistance programmes falling foul of a competition of scale and visibility.

Reimagining humanitarian effectiveness to consider how competitions of scale can draw resources away from other crises and increase the vulnerability of other communities and populations would 
require a much broader conceptualisation of project boundaries - geographically and politically as well as socially and economically (Leftwich, 1995). For now, at least, it is key to acknowledge that the conflict-disaster nexus stretches further than proximate crises in the same locale; divided disasters are also interlinked when their humanitarian responses exacerbate challenges and vulnerabilities for the affected populations on either side.

\section{References}

ABS CNN. (31 Mar 2009). 'Timeline: Kidnapping of the ICRC hostages by Abu Sayyaf Group', ABS CNN Accessed 6 October 2017. Online: http://news.abs-cbn.com/nation/03/31/09/timelinekidnapping-icrc-hostages-abu-sayyaf-group

Barnett, M. (2009) 'Evolution without progress? Humanitarianism in a world of hurt', International Organisation, 63(4). Pp. 621-663.

Bennett, R., Kottasz, R. (2000) 'Emergency fund-raising for disaster relief', Disaster Prevention and Management: An International Journal, 9(5). Pp. 352-360.

Borins, S. (2001) 'The new public management is here to stay', Canadian Public Administration, 38(1). Pp. 122-132.

Borton, J. (2009) 'Trends and Challenges in Measuring Effectiveness in the Humanitarian System'. In Measuring What Matters in Peace Operations and Crisis Management. S. Meharg (ed). Montreal: McGill-Queen's University Press.

Brancati, D. (2007) 'Political Aftershocks: The Impact of Earthquakes on Intrastate Conflict', Journal of Conflict Resolution, 51 (5). Pp. 715-743.

Crane, K., Dobbins, J., Miller, L.E., Ries, C.P., Chivvis, C.S., Haims, M.C., Overhaus, M., Schwartz, H.L., and Wilke, E. (2010) Building a more resilient Haitian State. Santa Monica, CA: Rand Corporation. Cooley, A., and Ron, J. (2002) 'The NGO Scramble: Organisational Insecurity and the Political Economy of Transnational Action', International Security, 27(1). Pp. 5-39.

Darnton, A. and Kirk, M. (2011) Finding Frames: New Ways to Engage the UK Public in Global Poverty, BOND.

Easterly, W. (2014) The Tyranny of Experts: Economists, dictators and the forgotton rights of the poor. New York: Basic Books.

Eastin, J. (2016) 'Fuel to the Fire: Natural Disasters and the Duration of Civil Conflict', International Interactions, 42 (2). Pp. 322-349.

Espada, F (ed). (2016) Essays on Humanitarian Effectiveness, London: Save the Children \& HCRI. 
Etherington, S. (1996) 'To the Millennium: The changing pattern of voluntary organisations'. In, Sweet Charity: The Role and Workings of Voluntary Organisations, Hanvey, C. and Philpot, T. (eds), pp.7-21. London: Routledge.

Ferguson, J. (1990) The Anti-Politics Machine: 'Development', Depoliticisation, and Bureaucratic Power in Lesotho. Cambridge: Cambridge University Press.

Field, J. (2017) 'What is appropriate and relevant assistance after a disaster? Accounting for culture(s) in the response to Typhoon Haiyan/Yolanda', International Journal of Disaster Risk Reduction, 22. Pp. 335-344.

Field, J. (2016) 'A Culture Clash? Typhoon Yolanda and the 'appropriateness' of humanitarian assistance in the Philippines', in Essays on Humanitarian Effectiveness, F. Espada (ed). London: Save the Children \& HCRI.

Fiori, J., Espada, F., Field, J., and Dicker, S. (2016) The Echo Chamber: Results, Management, and the Humanitarian Effectiveness Agenda. London: The Humanitarian Affairs Team \& Humanitarian and Conflict Response Institute.

FTS [Financial Tracking Service], (n.d. [a]), ‘Philippines - Bohol Earthquake Action Plan October 2013 - April 2014'. Accessed 22 Sept 2017. Available: https://fts.unocha.org/appeals/440/summary

FTS, (n.d.[b]), 'Philippines - Typhoon Haiyan Strategic Response Plan (November 2013 - October 2014) (Humanitarian response plan)'. Accessed 22 Sept 2017. Online: https://fts.unocha.org/appeals/441/summary

Gaillard, J.C., Clave, E., Kelman, I. (2008) 'Wave of Peace? Tsunami Disaster Diplomacyin Aceh, Indonesia', Geoforum, 39, 1. Pp. 511-526.

GMA News, (18 Sep 2008). 'Senator calls on AFP, PNP to secure aid workers in Mindanao', GMA, Accessed 6 Oct 2017. Online:

http://www.gmanetwork.com/news/news/regions/121159/senator-calls-on-afp-pnp-to-secureaid-workers-in-mindanao/story/

Gorz, A., (1989) Critique of Economic Reason. London: Verso Books, 1989.

Heijmans, A. (2009) 'The Social Life of Community-Based Disaster Risk Reduction: Origin, Politics and Framing'. Disaster Studies Working Paper 20, Aon Benfield UCL Hazard Research Centre.

Hilhorst, D. and Jansen, B. (2013) 'Humanitarian Space as Arena: A perspective in the everyday politics of aid', in D. Hilhorst (ed.), Disaster, Conflict and Society in Crisis: Everyday Politics of Crisis Response, Routledge: London.

Hilton, M., McKay, J., Crowson, N., \& Mouhot., J.F. (2013) The Politics of Expertise: How NGOs Shaped Modern Britain, Oxford: Oxford University Press [ebook].

Hopgood, S. (2013) Keepers of the Flame: Understanding Amnesty International. Ithaca: Cornell University Press. 
Hyndman, J. (2009) 'Siting conflict and peace in post-tsunami Sri Lanka and Aceh, Indonesia', Norsk Geografisk Tidsskrift - Norwegian Journal of Geography, 63(1). Pp. 89-96.

Hyndman, J. (2011) Dual Disasters: Humanitarian Aid after the 2004 Tsunami, Kumarian Press, Sterling, VA.

Hyndman, J. (2014) 'Human Security in the Face of Dual Disasters', In: Hobson, C., Bacon, P.,

Cameron, R. (eds.), Human Security and Natural Disasters, p.111-126. Routledge: London.

IDMC, (2014) 'Workshop report: Durable Solutions in Zamboanga'. Norwegian Refugee Council \& IDMC.

Kapoor, I. (2013) Celebrity Humanitarianism: The ideology of global charity, London: Routledge.

Kelman, I. (2011) Disaster Diplomacy: How Disasters Affect Peace and Conflict, Routledge: London.

Kennedy, J., Ashmore, J., Babister, E., and Kelman, I. (2008) 'The Meaning of "Build Back Better":

Evidence from Post-Tsunami Aceh and Sri Lanka', Journal of Contingencies and Crisis

Management, 16(1). Pp. 24-36.

Krause, M. (2014) The Good Project: Humanitarian Relief NGOs and the Fragmentation of Reason. University of Chicago Press: London. [ebook].

Kreutz, J. (2012) 'From Tremors to Talks: Do Natural Disasters Produce Ripe Moments for Resolving Separatist Conflicts?', International Interactions, 38 (4). Pp. 482-502.

Le Billon, P. and Waizenegger, A. (2007) 'Peace in the wake of disaster? Secessionist conflicts and the 2004 Indian Ocean tsunami', Trans. Inst. Br. Geogr. 32. Pp. 411-427.

Leftwich, A. (1995) 'Bringing politics back in: Towards a model of the developmental state', The Journal of Development Studies, 31(3). Pp. 400-427,

Leftwich, A. (1993) 'Governance, democracy and development in the Third World', Third World Quarterly, 14(3). Pp. 605-624.

Lindenberg, M. (2001) 'Are we at the cutting edge or the blunt edge? Improving NGO organizational performance with private and public sector strategic management frameworks', Non-profit Management and Leadership, 11(3): 247-270.

Malapit, H.J.L., Clemente, T.S. and Yunzal, C., (2003) ‘Does Violent Conflict Make Chronic Poverty More Likely? The Mindanao Experience', The Philippine Review of Economics, 40(2). Pp. 31-58.

Mitra, S. and J. Vivekananda, (2015) 'Compounding Risks: Disasters, Fragility and Conflict', Policy Brief, International Alert.

Moeller, S. D. (2006) "'Regarding the Pain of Others": Media, Bias and the Coverage of International Disasters'. Journal of International Affairs, 59 (2). Pp. 173-196.

Natsios, A., (2010) 'The Clash of the Counter-bureaucracy and Development'. Centre for Global Development Essay. Washington, D.C.: Centre for Global Development. 
Newland C.A. (2001) Public Management and Reform in the United States. In: Nolan B.C. (eds) Public Sector Reform. Palgrave Macmillan, London.

OCHA (14 Jan 2014), Philippines: Zamboanga and Basilan Emergency. Situation Report No. 15.

OCHA (20 April 2015), Accessed 26 Sept 2017. Online: 'Aid Worker Diary: Ensuring Humanitarian Aid for the Displaced in Zamboanga', UN OCHA, Online: http://www.unocha.org/country/topstories/all-stories/aid-worker-diary-ensuring-humanitarian-aid-displaced-zamboanga.

OCHA (2013), Philippines (Mindanao) Humanitarian Action Plan. Geneva: OCHA. http://www.unocha.org/cap/appeals/humanitarian-action-plan-philippines-mindanao-2013 OCHA (2014a), 'Humanitarian Bulletin' (1-31 October 2014), OCHA, Issue 29.

OCHA (2014b), 'Philippines Humanitarian Country Team Meeting Notes', 19 August 2014, Yuchengco Institute for Advanced Studies, RCBC Plaza, Tower II, Makati Christopher Pollitt, Managerialism and the Public Services: The Anglo-American Experience (Cambridge, MA: Basil Blackwell, 1990) OCHA (23 Dec 2013), Philippines: Zamboanga and Basilan Emergency. Situation Report No. 14. OCHA (23 Sept 2013), Philippines: Zamboanga and Basilan Emergency. Situation Report No. 3. OCHA (26 Sept 2013), Philippines: Zamboanga and Basilan Emergency. Situation Report No. 4. OCHA, (16 Dec 2013), Typhoon Haiyan. Situation Report No. 24.

OCHA, (3 Jan 2014), 'Zamboanga: A Forgotten Crisis in the Shadow of Haiyan'. Accessed 12 Sept 2017. Online: https://www.unocha.org/country/top-stories/all-stories/philippines-zamboangaforgotten-crisis-shadow-haivan

Ong, JC. (2015). Witnessing distant and proximal suffering within a zone of danger: Lay moralities of media audiences in the Philippines. International Communication Gazette, 1-16.

Orgad, S. (2013) 'Visualizers of solidarity: organizational politics in humanitarian and international development NGOs', Visual Communication, 12(3). Pp. 295-314.

Peters, K., and Budimir, M. (2016) When Disasters and Conflict Collide: Facts and Figures, Overseas Development Insitute, London.

Pollitt, C. (1990) Managerialism and the Public Services: The Anglo-American Experience. Cambridge, MA: Basil Blackwell.

ReliefWeb (2013), 'Philippines: Earthquake 2013', Accessed 24 Sept 2017. Online: https://reliefweb.int/disaster/eq-2013-000134-phl

Soriano, C. R. (2006), 'The Challenges of Relief and Rehabilitation Assistance in Ongoing Conflict: A Mindanao Case', Kasarinlan: Phiilppine Journal of Third World Studies, 26(1). Pp. 4-33.

Stirrat, J. (2006) 'Competitive Humanitarianism: Relief and the Tsunami in Asia', Anthropology Today, 22(5). Pp. 11-16.

Strachan, A. L. (December 2015). 'Conflict Analysis of Muslim Mindanao', GSDRC. 
Telford, J., and Cosgrove, J. (2006) 'Joint Evaluation of the International Response to the Indian Ocean Tsunami'. Synthesis Report. Tsunami Evaluation Coalition.

Thomas, A. (2014), 'Field Report. Philippines: Displaced and Forgotten in Zamboanga', Refugees International, 15 Dec 2014.

UNDP, (2011). Disaster-Conflict Interface: Comparative Experiences. United Nations Development Programme, Bureau of Crisis Prevention and Recovery.

UPI (1999), 'Kidnapped Belgian Aid Worker Released', Accessed 6 October 2017. Available: https://www.upi.com/Archives/1999/06/23/Kidnapped-Belgian-aid-workerreleased/8059199143000/

Valters, C. And Whitty, B. (2017) The Politics of the Results Agenda in DFID. ODI: London.

Vellema, S., Borras JR, S. M. and Lara JR, F. (2011) 'The Agrarian Roots of Contemporary Violent Conflict in Mindanao, Southern Philippines', Journal of Agrarian Change, 11. Pp. 298-320.

Waizenegger, A., and Hyndman, J. (2010) 'Two solitudes: post-tsunami and post-conflict in Aceh', Disasters, 34(3). Pp. 787-808.

Walch, C. (2015) 'Collaboration or obstruction? Rebel group behaviour during natural disaster relief in the Philippines', Political Geography, 43: 40-50.

Walton, O., (2017): Beyond disaster framing: exploring multi-mandate INGOs' representations of conflict, Third World Quarterly, DOI: 10.1080/01436597.2017.1350097

Wakolbinger, T. and Toyasaki, F. (2014) 'Impacts of Funding Systems on Humanitarian Operations', in Humanitarian Logistics: Meeting the challenge of preparing for and responding to disasters, Tatham, P. and Christopher, M. (eds). London: Kogan Page.

Watson, S. (2011) 'The "human" as referent object? Humanitarianism as securitization', Security Dialogue , 42(1). Pp. 3-20.

Wong, W. (2012) Internal Affairs: How the Structure of NGOs Transforms Human Rights, Ithaca: Cornell University Press.

Zeccola, P. (2011) 'Dividing disasters in Aceh, Indonesia: separatist conflict and tsunami, human rights and humanitarianism', Disasters, 35(2). Pp. 308-328. 